\title{
Factors related to changes in the quality of life among Polish adolescents and adults with cystic fibrosis over a I-year period
}

This article was published in the following Dove Press journal:

Patient Preference and Adherence

15 December 2015

Number of times this article has been viewed

\author{
Grażyna Dębska' \\ Henryk Mazurek ${ }^{2}$ \\ 'Faculty of Health and Medical \\ Studies, Andrzej Frycz Modrzewski \\ Krakow University, Krakow, \\ ${ }^{2}$ Department of Pneumonology and \\ Cystic Fibrosis, National Tuberculosis \\ and Lung Diseases Research Institute, \\ Rabka, Poland
}

Background: The aim of this study was to determine the effects of clinical factors, physical activity, and sociodemographic variables on 1-year changes in health-related quality of life (HRQoL) in Polish adolescents and adults with cystic fibrosis (CF).

Method: The study included 67 subjects with CF (mean age 21.1 \pm 5.1 years; range 14-37 years; 34 males and 33 females). The Cystic Fibrosis Quality of Life Questionnaire was used at baseline and after 1 year. Lung function data, body weight, and body height were extracted from medical records. Clinical assessment was performed with the Shwachman-Kulczycki scale.

Results: The highest scores in both HRQoL examinations came from the domains of physical and social functioning, and the lowest from future concerns, body image, and career concerns. No significant changes of Cystic Fibrosis Quality of Life Questionnaire scores were documented over a period of 1 year. Patients with better baseline spirometry results more frequently reported an improvement in the treatment issues (subjects with $\mathrm{FEV}_{1}>50 \%$ of predicted, $P=0.020$ ) and in the career concerns (patients with $\mathrm{FVC}>50 \%$ of predicted, $P=0.039$ ). The improvement in the career concerns also depended upon daily physical activity $(P=0.024)$, which was shown to modulate future concerns $(P=0.032)$, along with place of residence and living conditions $(P=0.003)$. Moreover, the time elapsed from the last pulmonary exacerbation was related to the change in social functioning $(P=0.026)$.

Conclusion: When planning treatment, attention should be paid to interventions which may improve HRQoL. Systematic chronic therapy improves lung function, related to treatment issues and career concerns. Maintaining good physical condition and activity may positively influence future and career concerns. Special attention must be devoted to patients living in rural areas and enduring difficult living conditions, as they are especially vulnerable to deterioration in future concerns.

Keywords: cystic fibrosis, lung function, physical activity, psychological support, respiratory rehabilitation, quality of life

\section{Introduction}

Cystic fibrosis (CF) is a hereditary disorder affecting mainly respiratory system and gastrointestinal tract. Thick mucus in the airways promotes chronic bacterial infections eventually leading to lung destruction, respiratory insufficiency, and preterm death. The outlook for patients with CF has improved in the past 20 years. Every year, an increased number of individuals with $\mathrm{CF}$ reach adulthood. ${ }^{1-5}$

The life expectancy of CF patients is usually determined by respiratory function. The deterioration in lung function is marked not only by a decrease in the forced expiratory volume in the 1 st second $\left(\mathrm{FEV}_{1}\right)$ of expiration, but also by the frequent occurrence of exacerbations and complications (eg, hemoptysis and pneumothorax). 1,3,4
Correspondence: Grażyna Dębska Faculty of Health and Medical Studies, Andrzej Frycz Modrzewski Krakow University, Herlinga-Grudzińskiego I, 30-705 Krakow, Poland

Tel +48 I 22524520

$\mathrm{Fax}+48 \quad 122524523$

Email gdebska@afm.edu.pl 
As the disease progresses, physical capabilities worsen. At the same time, daily therapy becomes more time-consuming and more complicated. Interpersonal relationships are also adversely affected, ${ }^{1,4,6-10}$ and may negatively influence the health-related quality of life (HRQoL)..$^{7-11}$

Undoubtedly, the clinical factors determine the prognosis and could influence the HRQoL. ${ }^{10,12-14}$ The progression of the illness and its interaction with clinical variables suggest that the longitudinal changes in HRQoL should be monitored in CF patients. ${ }^{10}$ Identification of factors influencing HRQoL could facilitate interventions, indirectly aiming at improvement of patient well-being. While HRQoL of individuals with $\mathrm{CF}$ from Western countries has been a subject of several previous studies, little is known on the quality of life in Polish patients with this condition. Due to limited availability of some treatments (eg, inhaled antibiotics) and worse socioeconomic conditions, the HRQoL of this group is not necessarily the same as previously reported.

The aims of this study were as follows: 1) to see if young $\mathrm{CF}$ patients hospitalized for intravenous treatment show changes in their HRQoL over a 1-year period, 2) to identify the relationships among HRQoL, clinical parameters (such as Shwachman-Kulczycki's [Sh-K] score, lung function), and socioeconomic status (ie, living conditions or place of residence), and 3 ) to identify potentially modifiable factors responsible for the 1-year changes in HRQoL.

\section{Materials and methods Design}

We used the longitudinal data collection model with reassessment performed during a subsequent episode of exacerbation with intravenous treatment required after a period of 10-14 months. Both examinations were conducted on the 4 th or 5 th day of hospitalization, after clinical stabilization of the patients. We tried to examine the patients with relatively comparable health status, to limit potential influence of subclinical inflammation inevitably exacerbating from the last antibiotic treatment. The study was approved by the Local Bioethical Committee at the Institute of Tuberculosis and Lung Disease (Decision no KE 29/2014).

\section{Participants}

Participants were selected from a pool of patients hospitalized due to pulmonary exacerbation at the Pneumonology and Cystic Fibrosis Department of the Tuberculosis and Lung Diseases Institute in Rabka Zdroj (Poland) between January 2004 and September 2004. Only patients older than 14 years of age, with frequent bronchopulmonary exacerbations (at least two hospitalizations in the last 12 months), with no prior history of substance abuse disorders, cognitive impairments, or other chronic illnesses, other than CF-related, were included. The examinations were conducted after written consent was obtained from all subjects; in the case of adolescents, written consent from the parents or caregiver was also required. Aside from the lack of informed consent, other exclusion criteria of the study were evidence of alcohol or drug abuse and history of mental or other clinically significant disease unrelated to $\mathrm{CF}$, whose sequelae and/or treatment might interfere with the results of the study.

Initially, 83 subjects were included to the study. During 1 year, six patients died due to $\mathrm{CF}$, one due to an accident, and four individuals withdrew from the second examination. Another five patients did not show an exacerbation requiring hospitalization in the time period of between 10 and 14 months after the first examination. Therefore, we eventually analyzed the data of 67 subjects.

\section{Measurements}

The Gee et al Cystic Fibrosis Quality of Life Questionnaire $(\mathrm{CFQ} \text { oL })^{12}$ was used to assess the HRQoL in adolescents and adults suffering from CF. This questionnaire has been translated into Polish and psychometrically validated. ${ }^{15}$ Previous reliability analysis has confirmed the relevance of this instrument for the purposes of our study. The validity of the Polish version was confirmed by high values of Cronbach's alpha coefficients $(>0.70),{ }^{15}$ comparable to the values obtained in the Italian study, ${ }^{16}$ and similar to the psychometric characteristics of the English version. ${ }^{15}$ The results obtained with the CFQoL were calculated using the original method. ${ }^{12}$ We measured the following individual domains: physical functioning, social functioning, treatment issues, chest symptoms, emotional functioning, future concerns, relationships, body image, and career concerns. Scores from individual domains were transformed into numeric values ranging between 0 and 100 (where 100 corresponded to the most positive HRQoL possible). ${ }^{15}$

Additionally, physical activity was measured using the activity scale, part of the Rotterdam Symptom Checklist (RSCL), ${ }^{17}$ which can be used as an autonomous tool. Numeric values on the scale refer to different types of physical activities: self-reliance/washing, moving around the house, doing housework, walking up stairs, temporary work, leaving the house, shopping, and going to work/school. The global score can range between 0 and 100 with higher values corresponding to higher levels of physical activity. An additional 
question expressly formulated for the purposes of this study, regarding physical fitness (self-assessed as good, average, or bad) was added. A sociodemographic interview questionnaire was also used to gather related data.

The same questionnaires were used in the re-assessment performed 1 year later. During the re-assessment, participants reported changes in their physical condition by comparing the current condition to that present 1 year before.

Lung function data $\left(\mathrm{FEV}_{1}, \mathrm{FVC}\right.$ [forced vital capacity]) and the body mass index, calculated as body mass in kilograms divided by the square of height in meters, were extracted from medical records. Clinical assessment was performed with the $\mathrm{Sh}-\mathrm{K}$ scale.

Between the first and the second examination, the occurrence of pulmonary exacerbations and the time elapsed since the last exacerbation were recorded.

\section{Statistical analysis}

We analyzed the influence of clinical factors, physical activity, and sociodemographic variables on HRQoL. Continuous variables were presented as arithmetic means \pm standard deviations; their normal distribution was tested using the KolmogorovSmirnov test. Initial spirometric values and HRQoL level were compared to the values obtained at the end of the follow-up using the Wilcoxon paired test. The spirometric values acquired during the first examination were additionally divided into two groups of impairment - mild to moderate $\left(\mathrm{FEV}_{1}\right.$ or $\mathrm{FVC}>50 \%$ of predicted) and severe $\left(\mathrm{FEV}_{1}\right.$ or $\left.\mathrm{FVC}<50 \%\right)$, and were subsequently analyzed. We divided our patients into only two subgroups, because a standard three-subgroup analysis $\left(\mathrm{FEV}_{1}<40 \%\right.$ vs $41 \%-69 \%$ vs $>70 \%$ ) was not feasible due to a limited number of patients with $\mathrm{FEV}_{1}<40 \%$ of predicted. Subsequently, we determined the proportion of patients whose quality of life improved over a 1-year period, deteriorated or remained the same, in order to identify factors influencing changes in every domain of HRQoL. Comparison between groups was conducted using Mann Whitney's and chi-square test. Statistical analysis of data was performed with Statistica 6.0 software (StatSoft, Tulsa OK, USA); $P$-value at the level of 0.05 was considered to be statistically significant.

\section{Results}

At the beginning of the study, the average age of the 67 participants was $21.1 \pm 5.1$ years; 44 of them $(65.7 \%)$ were over the age of 18 years. Mean age at CF diagnosis was $88.7 \pm 6.8$ years. The subjects' $\mathrm{FEV}_{1}$ was between $14.5 \%$ and $95.6 \%$ of predicted $(47.8 \% \pm 22.3 \%)$ and $\mathrm{FVC}$ between $21.2 \%$ and $107.5 \%(63.3 \% \pm 23.3 \%)$ (Table 1$)$.
Table I Spirometric indices and Shwachman-Kulczycki's (Sh-K) scale values at the first and the second examination $(n=67)$

\begin{tabular}{llll}
\hline Variable & Baseline & After I year & $P$-value \\
\hline Spirometry & & & \\
FEV (\% predicted) & $47.8 \pm 22.3$ & $40.2 \pm 19.6$ & $<0.00$ I \\
FVC (\% predicted) & $63.3 \pm 23.3$ & $57.4 \pm 20.5$ & 0.026 \\
FEV,/FVC ratio & $66.2 \pm 13.9$ & $61.0 \pm 14.0$ & $<0.00$ I \\
MMEF (\% predicted) & $35.8 \pm 25.7$ & $23.1 \pm 23.1$ & $<0.00$ I \\
Sh-K scale (points) & & & \\
General activity level & $17.4 \pm 6.5$ & $15.8 \pm 6.6$ & $<0.001$ \\
Physical examination & $14.7 \pm 4.9$ & $14.0 \pm 5.1$ & 0.014 \\
Physical development & $20.5 \pm 4.2$ & $19.6 \pm 4.9$ & 0.002 \\
and nutrition & & & \\
X-ray findings & $13.5 \pm 3.9$ & $12.7 \pm 4.2$ & 0.002 \\
Total Sh-K score & $64.2 \pm 18.6$ & $60.7 \pm 20.3$ & 0.041 \\
Body mass index & $18.0 \pm 2.8$ & $17.7 \pm 2.8$ & 0.562 \\
RSCL - physical activity & $86.0 \pm 19.9$ & $89.5 \pm 31.2$ & 0.256 \\
\hline
\end{tabular}

Note: Values presented as arithmetic means \pm standard deviations. Abbreviations: $\mathrm{FEV}_{1}$, forced expiratory volume in I second; FVC, forced vital capacity; RSCL, Rotterdam Symptom Checklist; MMEF, maximum midexpiratory flow.

Fifteen patients resided in villages and 21 in small towns. The vast majority of the study group assessed their living conditions as good or very good 52 (77.6\%), including 29 (43.3\%) of respondents residing in large cities and 23 (34.3\%) from villages and small towns. Poor housing conditions were reported by $22.5 \%$ of the surveyed individuals $(n=15)$, including $15 \%$ of inhabitants from villages and small towns $(n=10)$ and $7.5 \%$ of those living in large cities $(n=5)$. In general, large city inhabitants more often rated their living conditions as good or very good.

The patients' assessment based on spirometry and Sh-K scale, as well as the average scores of the CFQoL domains are presented in Tables 1 and 2. Severe impairment of $\mathrm{FEV}_{1}$ $(<50 \%$ of predicted value) and FVC was observed in 34 and 22 subjects, respectively. Fifty-four subjects (80.6\%) were infected with Pseudomonas aeruginosa, and 12 (17.9\%) have been diagnosed with diabetes mellitus.

At the first examination, 16 patients $(24 \%)$ described their physical condition as bad. Thirty two subjects (48\%) described their condition as average, and the remaining 19 (28\%) described their physical condition as good. Physical activity was self-assessed as good by 47 patients, as average by 6 , and as impaired by 14 subjects.

There was an 11.8-month time span between the two measurements of 67 subjects. During the 1-year-long time period, exacerbations of pulmonary disease were observed in 53 subjects $(79 \%)$. Nine patients $(13 \%)$ had more than three exacerbations. Most of the participants $(n=41,61.2 \%)$ experienced their last pulmonary exacerbation $<6$ months prior to their second examination. Average spirometric values, as 
Table 2 Quality of life scores across all domains at the first and second examinations $(n=67)$

\begin{tabular}{lllllll}
\hline Variable & Baseline & After I year & P-value & $\begin{array}{l}\text { Subjects with } \\
\text { HRQoL } \\
\text { improvement (\%) }\end{array}$ & $\begin{array}{l}\text { Subjects with } \\
\text { the same } \\
\text { HRQoL (\%) }\end{array}$ & $\begin{array}{l}\text { Subjects with } \\
\text { HRQoL } \\
\text { deterioration (\%) }\end{array}$ \\
\hline Physical functioning & $73.1 \pm 22.1$ & $69.1 \pm 25.3$ & $0.08 I$ & 32.8 & 6.0 & 61.2 \\
Social functioning & $72.5 \pm 25.4$ & $75.0 \pm 35.6$ & 0.550 & 49.3 & 13.4 & 37.3 \\
Treatment issues & $66.2 \pm 26.4$ & $63.8 \pm 26.9$ & 0.501 & 44.8 & 17.9 & 37.3 \\
Chest symptoms & $63.1 \pm 26.9$ & $60.5 \pm 25.6$ & 0.411 & 32.8 & 13.4 & 53.8 \\
Emotional functioning & $68.1 \pm 22.3$ & $65.7 \pm 25.7$ & 0.379 & 38.8 & 6.0 & 55.2 \\
Future concerns & $50.3 \pm 20.5$ & $48.0 \pm 24.0$ & 0.262 & 40.3 & 11.9 & 47.7 \\
Relationships & $57.0 \pm 22.0$ & $54.7 \pm 23.8$ & 0.265 & 44.8 & 3.0 & 52.2 \\
Body image & $54.9 \pm 26.9$ & $53.0 \pm 28.5$ & 0.270 & 37.3 & 17.2 & 44.8 \\
Career concerns & $56.9 \pm 23.3$ & $52.0 \pm 24.4$ & 0.063 & 35.8 & 13.4 & 50.8 \\
Total quality of life & $63.1 \pm 16.9$ & $60.3 \pm 18.0$ & 0.114 & 40.3 & 1.5 & 58.2 \\
score & & & & & &
\end{tabular}

Note: Values presented as arithmetic mean \pm standard deviation.

Abbreviation: HRQoL, health-related quality of life.

well as results of Sh-K scale assessments, were significantly lower than at the first examination (Table 1).

Our participants presented with relatively high RSCL scores, both at the baseline and after 1-year follow-up (86.0 \pm 19.9 and 89.5 \pm 31.2 , respectively). Most evident limitations were observed in the case of temporary work (in $26.7 \%$ of the study subjects), going to work/school (20.5\%), and shopping (12.8\%). Approximately, $50 \%$ of the study participants self-assessed their physical fitness as average, $28 \%$ as good, and $22 \%$ as poor.

The highest scores in both HRQoL examinations came from the domains of physical and social functioning. The lowest scores were found in the domains of future concerns (in both examinations: $50.3 \pm 20.5$ and $48.0 \pm 24.0$ ), body image (54.9 \pm 26.9 and 53.0 \pm 28.5 ), and career concerns (56.9 \pm 23.3 and 52.0 \pm 24.4$)$. An analysis of the CFQoL scores in our group indicated no significant change across all domains over a period of 1 year (Table 2). The smallest difference in HRQoL was found in the domain of body image, while the greatest changes were found in the domain of career concerns and physical functioning.

The relationships among changes in all HRQoL domains and in clinical assessments performed with the Sh-K scale, physical activity, and body mass index were not significant $(P=0.06)$.

Despite the lack of significant changes in HRQoL over the 1-year period, significant relationships were found among individual patients between the changes in two domains of HRQoL and the results of spirometry in the first examination. Most patients with $\mathrm{FEV}_{1}$ values $>50 \%$ of predicted $(\mathrm{n}=19$, $58 \%$ ) reported an improvement in the treatment issues, compared with $29 \%(n=10)$ of those with severe impairment
$(P=0.020)$. Patients who reported an improvement in the career concerns were more frequently found in the group with FVC values $>50 \%$ of predicted than with lower $(\mathrm{n}=19,42 \%$ vs $\mathrm{n}=4,14 \% ; P=0.039$ ). A significant relationship was also found between the change in the domain of career concerns and perception of physical condition at the first examination. The percentage of participants who reported an improvement in career concerns was found to be $47 \%, 34 \%$, and $19 \%$ in those that reported their physical condition as good, average, and poor, respectively $(P=0.024)$.

A significant relationship was found between the time elapsed from the last pulmonary exacerbation and the change in the domain of social functioning. An improvement in this domain was reported by 24 patients $(58.5 \%)$ whose last pulmonary exacerbation occurred $<6$ months before the second examination. Among the 26 participants whose last pulmonary exacerbation took place 6 months or more before the second examination, an improvement in social functioning was observed by eight subjects $(30.8 \%, P=0.026)$.

Further analysis found a statistically significant relationship between daily physical activity at the first examination and the change in the domain of future concerns. The percentages of patients who reported an improvement in future concerns were found to be $36 \%, 33 \%$, and $29 \%$ among those who reported their ability to perform daily tasks as good, average, and impaired, respectively $(P=0.032)$.

Significant relationships were found between living conditions and changes in the domain of future concerns. The majority of participants who assessed their living conditions as very $\operatorname{good}(\mathrm{n}=13,68.4 \%)$ also reported an improvement in this domain, compared with $29 \%$ of those with poor, average, or good living conditions $(P=0.003)$. 
Residents of rural areas constituted the largest percentage of participants ( $86.7 \%$ ); their perceptions of future concerns increased or remained unchanged. A similar pattern was observed in $57 \%$ of patients living in small towns and in $48 \%$ of those residing in urban areas $(P=0.051)$. Further analysis found no significant relationship between changes in HRQoL and other sociodemographic variables.

\section{Discussion}

Despite significant reductions in lung function and clinical features, we did not find any changes in HRQoL during the 1-year period. Among individual patients, changes in two domains of HRQoL (treatment issues and career concerns) depended upon spirometry results. Additionally, the changes in the career concerns were related to the physical condition. Changes in perception regarding future concerns depended on physical activity, place of residence, and living conditions, while the variation in social functioning was related to the time elapsed since the last pulmonary exacerbation.

Clinical deterioration documented in our patients was an inevitable consequence of the progressive nature of CF. A review of literature led to the conclusion that $\mathrm{FEV}$, values decrease by approximately $1.25 \%$ to $3.6 \%$ of predicted over the course of 1 year. ${ }^{18}$ In our study, an average decrease in $\mathrm{FEV}_{1}$ amounted to $7.9 \%$. Such a considerable decrease in $\mathrm{FEV}_{1}$ was observed in a severely deprived population, with high prevalence of chronic $P$. aeruginosa infection and limited access to inhaled antibiotic therapy. A similar value of yearly decline in $\mathrm{FEV}_{1}$ (7.6\%) of Polish patients not receiving inhaled tobramycin was observed by Stelmach et al. ${ }^{19}$

Our patients often presented with advanced respiratory changes and were frequently infected with $P$. aeruginosa. The high rate of $\mathrm{FEV}_{1}$ decrease observed throughout the course of this study might also result from limited access to inhaled antibiotic (ie, tobramycin) in Poland. A previous study confirmed the beneficial effects of inhaled tobramycin in CF, namely, an improvement in $\mathrm{FEV}_{1}$ and a lower incidence of pulmonary exacerbations. ${ }^{20}$ This highlights that the population of $\mathrm{CF}$ patients from Eastern Europe differs from the subjects from Western countries not only in terms of different mutation structure, but also with regard to treatment availability, which is eventually reflected by their shorter life span.

Although our patients showed a decrease in the spirometric indices and Sh-K scores, their HRQoL scores have not changed significantly over the course of 1 year. Also, Congleton et $\mathrm{al}^{21}$ found that HRQoL of $152 \mathrm{CF}$ patients (older than 16 years of age) did not change significantly over a period of 1 year. Sawyer et $\mathrm{al}^{22}$ conducted a study of adolescents with $\mathrm{CF}$ and also found no significant changes in their physical and social activity over a 2 -year period of observation, despite deterioration in the physical status. Goldbeck et $\mathrm{a}^{23}$ observed 108 adolescents and adults (15-47 years of age) with $\mathrm{CF}$ for a period of 18 months, and found no change in the HRQoL during that period. Additionally, the course of HRQoL was not dependent on the changes in $\mathrm{FEV}_{1} \cdot{ }^{21} \mathrm{It}$ is difficult to directly compare the results of the aforementioned studies as the authors used different questionnaires to measure HRQoL. The lack of significant changes in HRQoL might result from a relatively small number of examined subjects or from the fact that the HRQoL of hospitalized patients is relatively stable and not prone to long-term changes. However, it cannot be excluded that some aspects of HRQoL may not be sensitive to changes over time and longer observation period is needed to prove significant differences.

The results of previous studies suggest that inhaled tobramycin could positively affect HRQoL; in particular, patient's career or educational aspirations may be less affected. ${ }^{20}$ Weiner et al, ${ }^{24}$ following a systematic review of literature, found that the use of inhaled tobramycin can improve HRQoL, particularly in the domain of physical functioning.

Despite the lack of significant differences in the assessment of HRQoL between the second and the first examination, interrelationships between some variables and individual changes in HRQoL were found. In particular, an interrelationship was found between the level of spirometric impairments reported at the first examination and changes in two HRQoL domains: treatment issues and career concerns. Reduced lung function resulted in a growing percentage of patients who reported deterioration in these domains.

A significant interrelationship was also found between the time elapsed since the last pulmonary exacerbation and change in the social functioning. A shorter interval was associated with a larger percentage of patients who reported an improvement in social functioning. A possible reason for this may be a subjective improvement in health due to the recent intravenous treatment, which can have a positive impact on physical fitness (eg, leaving the house), and thus on social functioning. Intensive antibiotic therapy leads to an overall improvement in general and respiratory health, which lasts for a certain amount of time. Moreover, it cannot be excluded that the patients with longer time elapsed from the last exacerbation might show gradual, slow, and hardy noticeable deterioration, eventually leading to lower HRQoL. 
Another explanation may stem from the fact that the patients (especially those living alone) established a close relationship with medical staff during hospitalization, which transiently improved their social functioning.

The place of residence and living conditions were particularly relevant with regard to the sociodemographic factors. Better living conditions were associated with an increased percentage of patients who reported an improvement in the domain of future concerns over a 1-year period. A similar issue was observed for urban residents. These results are troubling and suggest that particular attention should be given to residents of rural areas. A high percentage of this group reported their future concerns as becoming worse or remaining unchanged. One can assume that living in a rural area might be associated with lower socioeconomic status and thus limits access to hospitals and other medical facilities with competence in CF treatment.

While the level of physical activity in the sample had not changed significantly over the year, individual impairments did influence future concerns. Impaired physical activity was reflected in a lower percentage of subjects reporting improvements in this domain. It was also found that as the perception of physical condition worsened, career concerns were more likely to deteriorate or remain the same (Table 3).

A formal assessment of HRQoL has been rarely used in the literature; however, various authors emphasize the use of physical exercise training in order to improve clinical status, physical condition, and fitness..$^{25,26}$ Therefore, it can be assumed that good maintenance of physical condition positively influences HRQoL in both physical and psychosocial spheres. Hebestreit et $\mathrm{al}^{27}$ observed that a 6-month physical conditioning program led not only to improved

Table 3 Sensitive quality of life (QoL) domains and list of possible interventions

\begin{tabular}{|c|c|c|}
\hline QoL domain & Positive influence & $\begin{array}{l}\text { Possible } \\
\text { interventions }\end{array}$ \\
\hline Treatment issues & - $\mathrm{FEV}_{1}>50 \%$ predicted & - Optimal treatment \\
\hline Career concerns & $\begin{array}{l}\text { - FVC }>50 \% \text { predicted } \\
\text { - Perception of physical } \\
\text { condition }\end{array}$ & $\begin{array}{l}\text { - Optimal treatment } \\
\text { - Regular exercise }\end{array}$ \\
\hline Social functioning & $\begin{array}{l}\text { Short period from } \\
\text { last exacerbation }\end{array}$ & $\begin{array}{l}\text { - Periodical } \\
\text { (preventive) } \\
\text { therapy? }\end{array}$ \\
\hline Future concerns & $\begin{array}{l}\text { - Ability to perform } \\
\text { daily activities } \\
\text { - Living conditions } \\
\text { - Residing in cities }\end{array}$ & $\begin{array}{l}\text { - Optimal treatment } \\
\text { - Social support }\end{array}$ \\
\hline
\end{tabular}

Abbreviations: $\mathrm{FEV}$, forced expiratory volume in the I second; FVC, forced vital capacity. physical fitness and lung function, but also to higher subjective health perception, maintained after the intervention concluded. However, patients from our study were noted to rarely exercise regularly.

The average values of the assessment of HRQoL in both examinations were relatively high in most HRQoL domains $(>50)$, regardless of the progression of the illness. The lack of changes in the HRQoL over time might have resulted from the presence of effective CF coping mechanisms, short observation period, or strict patient selection. Patients, whose data were not re-assessed, had low scores on only one HRQoL domain at the first examination. Diminished physical functioning and lower $\mathrm{FEV}_{1}$ in patients who died before the second examination may be related to a poor prognosis. In a recent study of Abbott et al, ${ }^{28}$ the physical functioning domain of the Quality of Life Questionnaire was strongly associated with survival. This finding suggests that patientreported HRQoL, particularly in this domain, could serve as a prognostic measure of survival independent of other measures, ie, $\mathrm{FEV}_{1}$ value, which is considered a prognostic factor.

After reviewing the available literature, arguments on the lack of changes in HRQoL over a period of time, despite progression of the illness, suggest that HRQoL should be considered as a trait rather than a condition or state. Researchers propose that patient's personality and the presence of a social support network may have a bigger impact on the HRQoL than any particular clinical variable. ${ }^{28}$ In a recent study of Besier et al, ${ }^{29}$ patients of both sexes with a partner, reported higher life satisfaction than those without a partner. The higher life satisfaction associated with having a partner might have beneficial effects on medical outcomes. This specific aspect of the HRQoL was not assessed in our study.

The possible limitations of our study include the small size of the sample, which contained both adolescents and adults. However, the proportion of the youngest participants ( $<18$ years of age) was low and amounted to only $21.7 \%$ $(n=18)$. Moreover, we did not estimate an optimum sample size for this clearly observational study. Another profoundly limiting factor was relatively high drop-out rate of our patients and the short period of observation. During result interpretation, it is important to take into account the fact that some aspects of HRQoL may not be sensitive to changes over time. Thus, it was difficult to compare the results of this study with those of other researchers as a variety of different questionnaires were used to assess the HRQoL in related literature. Another limitation of our study was that 
patient data were collected during hospitalization for an exacerbation, which potentially could be of differing severity. However, all examinations were done after 4-5 days of antibiotic treatment, following improvement and clinical stabilization of patients. Previous study confirmed that a half of patients with acute pulmonary exacerbations show spirometric improvement after 4-6 days of intravenous antibiotic therapy. ${ }^{30}$

\section{Conclusion}

In spite of observable interrelationships, the importance of clinical and functional factors in the HRQoL changes was difficult to determine. Probably, the HRQoL across many domains was also influenced by other factors than the ones analyzed during this study. Nevertheless, when planning treatment, attention should be paid to certain interventions aiming to improve HRQoL in the domains of future concerns, career concerns, and social functioning. These include optimal treatment (to maintain a better lung function), good maintenance of physical condition, and a high level of physical activity in everyday life. The latter finding seems particularly important as it is potentially prone to intervention. Special attention must be devoted to patients residing in rural areas or enduring difficult living conditions. This warrants being investigated further in large longitudinal studies.

\section{Disclosure}

The authors report no conflicts of interest in this work.

\section{References}

1. Davis PB. Cystic fibrosis since 1938. Am J Respir Crit Care Med. 2006;173(5):475-482.

2. Flume PA, O'Sullivan BP, Robinson KA, et al. Cystic fibrosis pulmonary guidelines: chronic medications for maintenance of lung health Am J Respir Crit Care Med. 2007;176(10):957-969.

3. Orenstein DM, Winnie GB, Altman H. Cystic fibrosis: a 2002 update. J Pediatr. 2002;140(2):156-164.

4. O'Sullivan BP, Freedman SD. Cystic fibrosis. Lancet. 2009;373(9678): 1891-1904.

5. Staab D, Wenninger K, Gebert N, et al. Quality of life in patients with cystic fibrosis and their parents: what is important besides disease severity? Thorax. 1998;53(9):727-731.

6. Sawyer SM, Tully MA, Dovey ME, Colin AA. Reproductive health in males with cystic fibrosis: knowledge, attitudes, and experiences of patients and parents. Pediatr Pulmonol. 1998;25(4):226-230.

7. Britto MT, Kotagal UR, Hornung RW, Atherton HD, Tsevat J, Wilmott RW. Impact of recent pulmonary exacerbations on quality of life in patients with cystic fibrosis. Chest. 2002;121(1):64-72.

8. Burker EJ, Sedway J, Carone S. Psychological and educational factors: better predictors of work status than FEV1 in adults with cystic fibrosis. Pediatr Pulmonol. 2004;38(5):413-418.

9. Dobbin CJ, Bye PT. Adults with cystic fibrosis: meeting the challenge! Intern Med J. 2003;33(12):593-597.
10. Gee L, Abbott J, Hart A, Conway SP, Etherington C, Webb AK. Associations between clinical variables and quality of life in adults with cystic fibrosis. J Cyst Fibros. 2005;4(1):59-66.

11. Steinkamp G, Wiedemann B. Relationship between nutritional status and lung function in cystic fibrosis: cross sectional and longitudinal analyses from the German CF quality assurance (CFQA) project. Thorax. 2002;57(7):596-601.

12. Gee L, Abbott J, Conway SP, Etherington C, Webb AK. Development of a disease specific health related quality of life measure for adults and adolescents with cystic fibrosis. Thorax. 2000; 55(11):946-954.

13. Gee L, Abbott J, Conway SP, Etherington C, Webb AK. Validation of the SF-36 for the assessment of quality of life in adolescents and adults with cystic fibrosis. J Cyst Fibros. 2002;1(3):137-145.

14. Gee L, Abbott J, Conway SP, Etherington C, Webb AK. Quality of life in cystic fibrosis: the impact of gender, general health perceptions and disease severity. J Cyst Fibros. 2003;2(4):206-213.

15. Debska G, Mazurek H. Validation of Polish version of CFQoL in patients with cystic fibrosis. Pol Merkur Lekarski. 2007;23(137):340-343.

16. Monti F, Lupi F, Gobbi F, et al. Validation of the Italian version of the Cystic Fibrosis Quality of Life Questionnaire (CFQoL), a disease specific measure for adults and adolescents with cystic fibrosis. $J$ Cyst Fibros. 2008;7(2):116-122.

17. Ravaioli A, Buda P, Fava C, et al. Assessment of the RSCL quality of life instrument during chemotherapy in an Italian setting. Qual Life Res. 1996;5(5):491-495.

18. Que C, Cullinan P, Geddes D. Improving rate of decline of FEV1 in young adults with cystic fibrosis. Thorax. 2006;61(2):155-157.

19. Stelmach I, Korzeniewska A, Stelmach W. Long-term benefits of inhaled tobramycin in children with cystic fibrosis: first clinical observations from Poland. Respiration. 2008;75(2):178-181.

20. Iles R, Legh-Smith J, Drummond M, Prevost A, Vowler S. Economic evaluation of tobramycin nebuliser solution in cystic fibrosis. $J$ Cyst Fibros. 2003;2(3):120-128.

21. Congleton J, Hodson ME, Duncan-Skingle F. Do Nottingham Health Profile scores change over time in cystic fibrosis? Respir Med. 1998;92(2):268-272.

22. Sawyer MG, Reynolds KE, Couper JJ, et al. Health-related quality of life of children and adolescents with chronic illness - a two year prospective study. Qual Life Res. 2004;13(7):1309-1319.

23. Goldbeck L, Zerrer S, Schmitz TG. Monitoring quality of life in outpatients with cystic fibrosis: feasibility and longitudinal results. $J$ Cyst Fibros. 2007;6(3):171-178.

24. Weiner JR, Toy EL, Sacco P, Duh MS. Costs, quality of life and treatment compliance associated with antibiotic therapies in patients with cystic fibrosis: a review of the literature. Expert Opin Pharmacother. 2008;9(5):751-766.

25. Orenstein DM, Hovell MF, Mulvihill M, et al. Strength vs aerobic training in children with cystic fibrosis: a randomized controlled trial. Chest. 2004;126(4):1204-1214.

26. Selvadurai HC, Blimkie CJ, Meyers N, Mellis CM, Cooper PJ, Van Asperen PP. Randomized controlled study of in-hospital exercise training programs in children with cystic fibrosis. Pediatr Pulmonol. 2002;33(3):194-200.

27. Hebestreit H, Kieser S, Junge S, et al. Long-term effects of a partially supervised conditioning programme in cystic fibrosis. Eur Respir $J$. 2010;35(3):578-583.

28. Abbott J, Hart A, Morton AM, Dey P, Conway SP, Webb AK. Can health-related quality of life predict survival in adults with cystic fibrosis? Am J Respir Crit Care Med. 2009;179(1):54-58.

29. Besier T, Schmitz TG, Goldbeck L. Life satisfaction of adolescents and adults with cystic fibrosis: impact of partnership and gender. JCyst Fibros. 2009;8(2):104-109.

30. Blumer JL, Saiman L, Konstan MW, Melnick D. The efficacy and safety of meropenem and tobramycin vs ceftazidime and tobramycin in the treatment of acute pulmonary exacerbations in patients with cystic fibrosis. Chest. 2005;128:2336-2346. 
Patient Preference and Adherence

Dovepress

\section{Publish your work in this journal}

Patient Preference and Adherence is an international, peer-reviewed, open access journal that focuses on the growing importance of patient preference and adherence throughout the therapeutic continuum. Patient satisfaction, acceptability, quality of life, compliance, persistence and their role in developing new therapeutic modalities and compounds to optimize

clinical outcomes for existing disease states are major areas of interest for the journal. This journal has been accepted for indexing on PubMed Central. The manuscript management system is completely online and includes a very quick and fair peer-review system, which is all easy to use. Visit http://www. dovepress.com/testimonials.php to read real quotes from published authors.

Submit your manuscript here: http://www.dovepress.com/patient-preference-and-adherence-journal 